\title{
Calix[4]pyrrole-capped metalloporphyrins as a ditopic receptor models for anions
}

\author{
Pradeepta K. Panda and Chang-Hee Lee* \\ Department of Chemistry Kangwon National University Chun-Chon, 200-701 Korea
}

\section{General procedure}

Proton NMR spectra (400 MHz, Bruker IFS 48) were recorded in $\mathrm{CDCl}_{3}$ using TMS as the internal standard. High and Low resolution FAB mass spectra were obtained on AUTO SPEC M-363 high-resolution mass spectrometer. Column chromatography was performed over silica gel (Merck, 230-400 mesh). Pyrrole was distilled at atmospheric pressure from $\mathrm{CaH}_{2}$. Both $\mathrm{CH}_{2} \mathrm{Cl}_{2}$ and $\mathrm{CHCl}_{3}$ (reagent grade) were distilled from $\mathrm{K}_{2} \mathrm{CO}_{3}$ to eliminate traces of acid. All other reagents were obtained from Aldrich and used as received unless noted otherwise. 
Fig. $1{ }^{\cdot 1} \mathrm{H}$ NMR spectrum of 3.

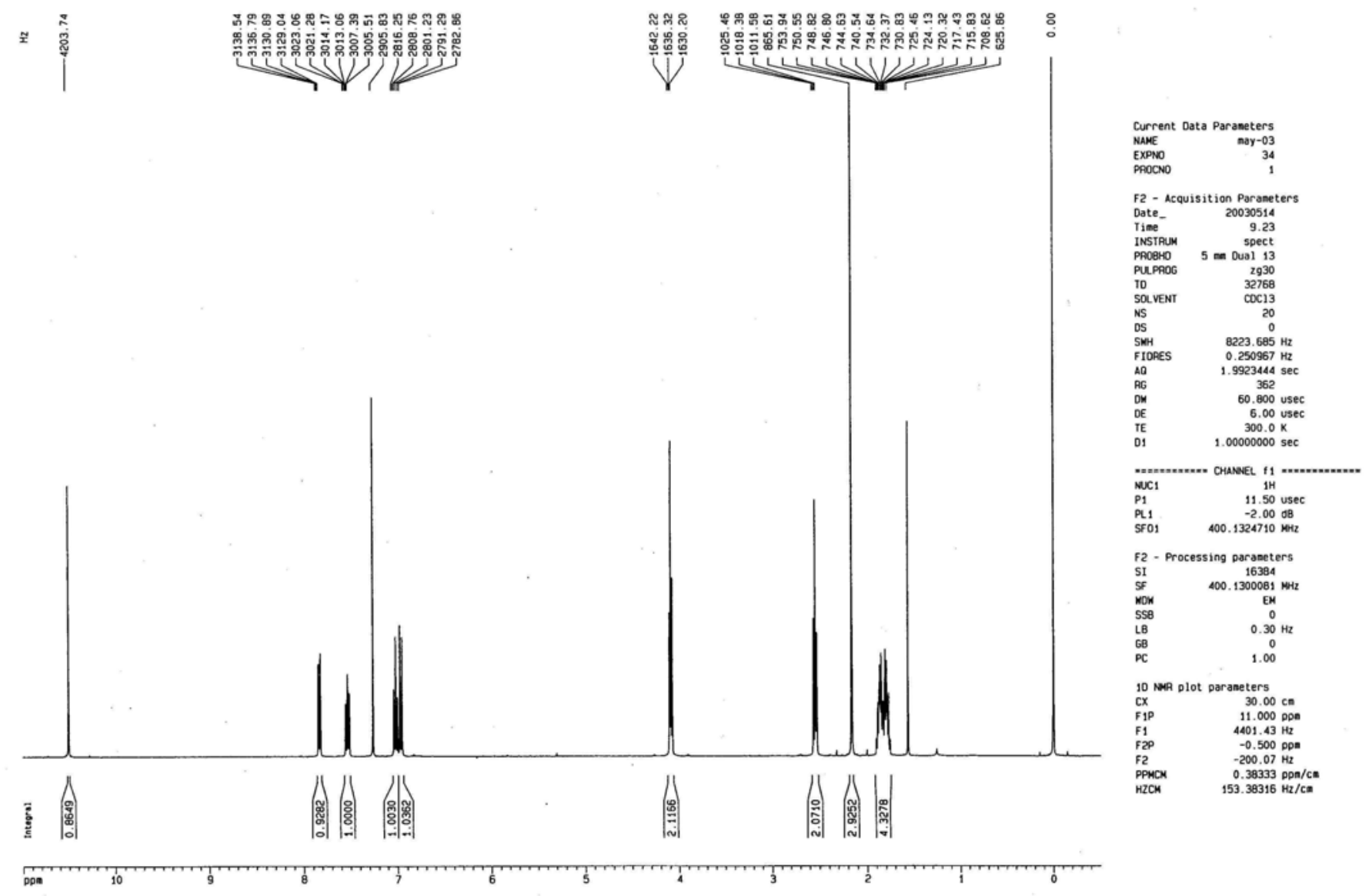


Fig. 2. EI- Mass spectrum of 3.

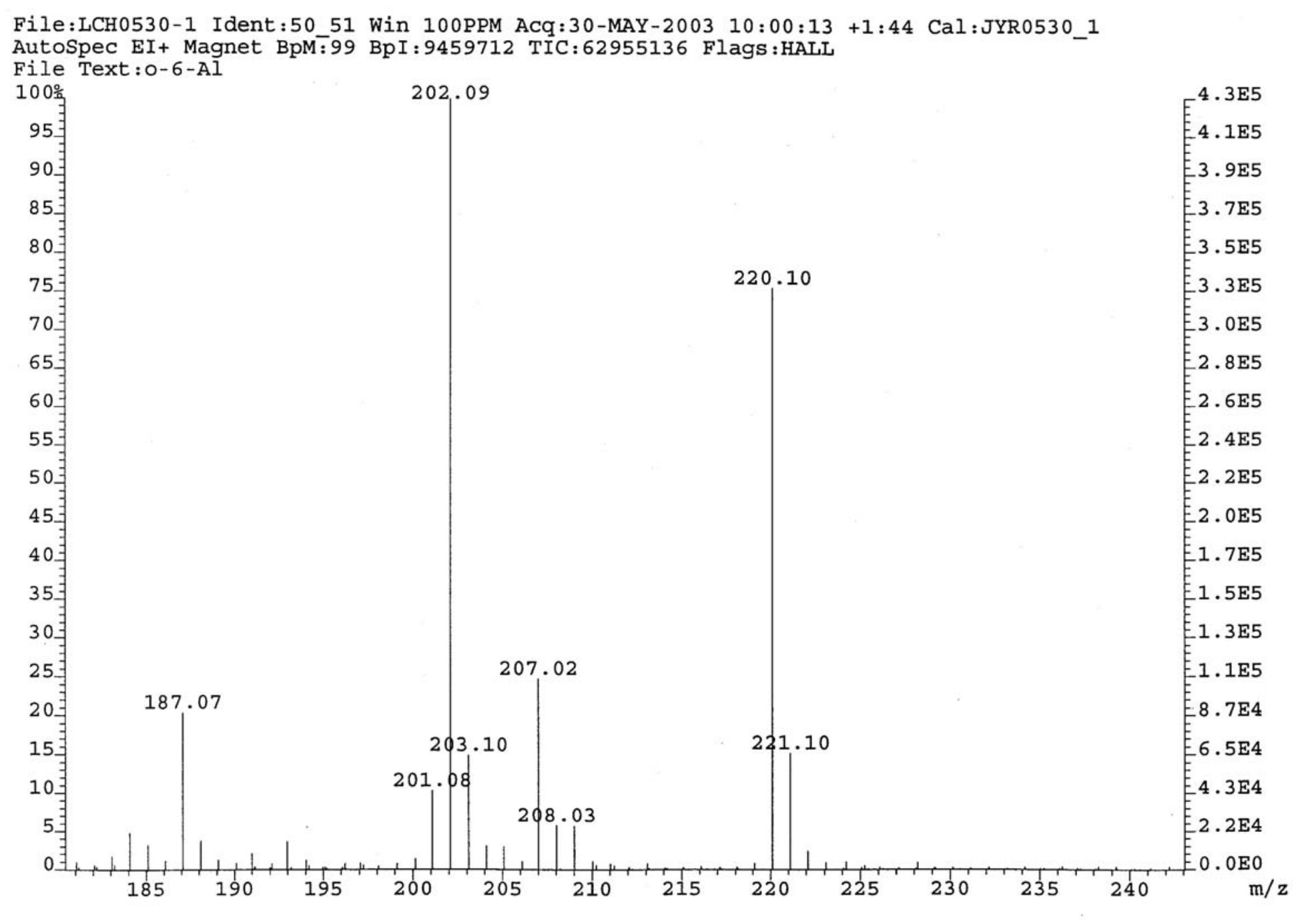


Fig.3. ${ }^{1} \mathrm{H}$ NMR spectrum of cis-Free base of 5,15-Bis-[2-(5-0xo-hexyloxy)-phenyl]10,20-bis-(2,4,6-trimethyl-phenyl) porphyrin (4).


F2 - Acquisition Paraneter

Date_ Acquisition Paraneters

Tine

13.44
INSTAUM

5 man Dual 13

2930
PUPAO6

SQ VENT

NS

sent

0.250967 Hiz

1.9923444 sec

$\begin{array}{ll}\text { AG } & 181 \\ \text { OW } & 60.800 \text { usec }\end{array}$

DE $6.00 \mathrm{usec}$

$\begin{array}{ll} & 300.0 \mathrm{~K} \\ \mathrm{D} 1 & 1.00000000 \mathrm{sec}\end{array}$

............. Chanel. f1 .........

$\begin{array}{ll}\text { NuC1 } & 1 \mathrm{H} \\ \text { P1 } & 11.50 \text { usec }\end{array}$

$\begin{array}{ll}\text { P1 } & 11.50 \text { usec } \\ \text { PL1 } & -2.00 \mathrm{~dB}\end{array}$

SFO1 400.1324710 Ne12

F2 - Processing parameters

SI Processing parameters

$\begin{array}{lr}\text { SI } & 16384 \\ \text { SF } & 400.1300206 \\ \text { MHZ }\end{array}$

NOW EM

$\begin{array}{ll}\mathrm{SSB} & 0 \\ \mathrm{LB} & 0.30 \mathrm{~Hz}\end{array}$

PC

10 Not plot paraneters

CX $\quad 30.00 \mathrm{ce}$

$\begin{array}{ll}\text { FIP } & 10.500 \mathrm{ppm} \\ \text { FI } & 4201.37 \mathrm{~Hz}\end{array}$

F2P $\quad-4.000 \mathrm{ppm}$

F2 $\quad-1600.52 \mathrm{~Hz}$

$\begin{array}{ll}\text { PPMCM } & 0.48333 \mathrm{ppm} / \mathrm{cm} \\ \text { HZCM } & 193.39619 \mathrm{~Hz} / \mathrm{cm}\end{array}$ 
Fig.4. ${ }^{13} \mathrm{C}$ NMR spectrum of cis-Free base of 5,15-Bis-[2-(5-oxo-hexyloxy)-phenyl]10,20-bis-(2,4,6-trimethyl-phenyl) porphyrin (4).

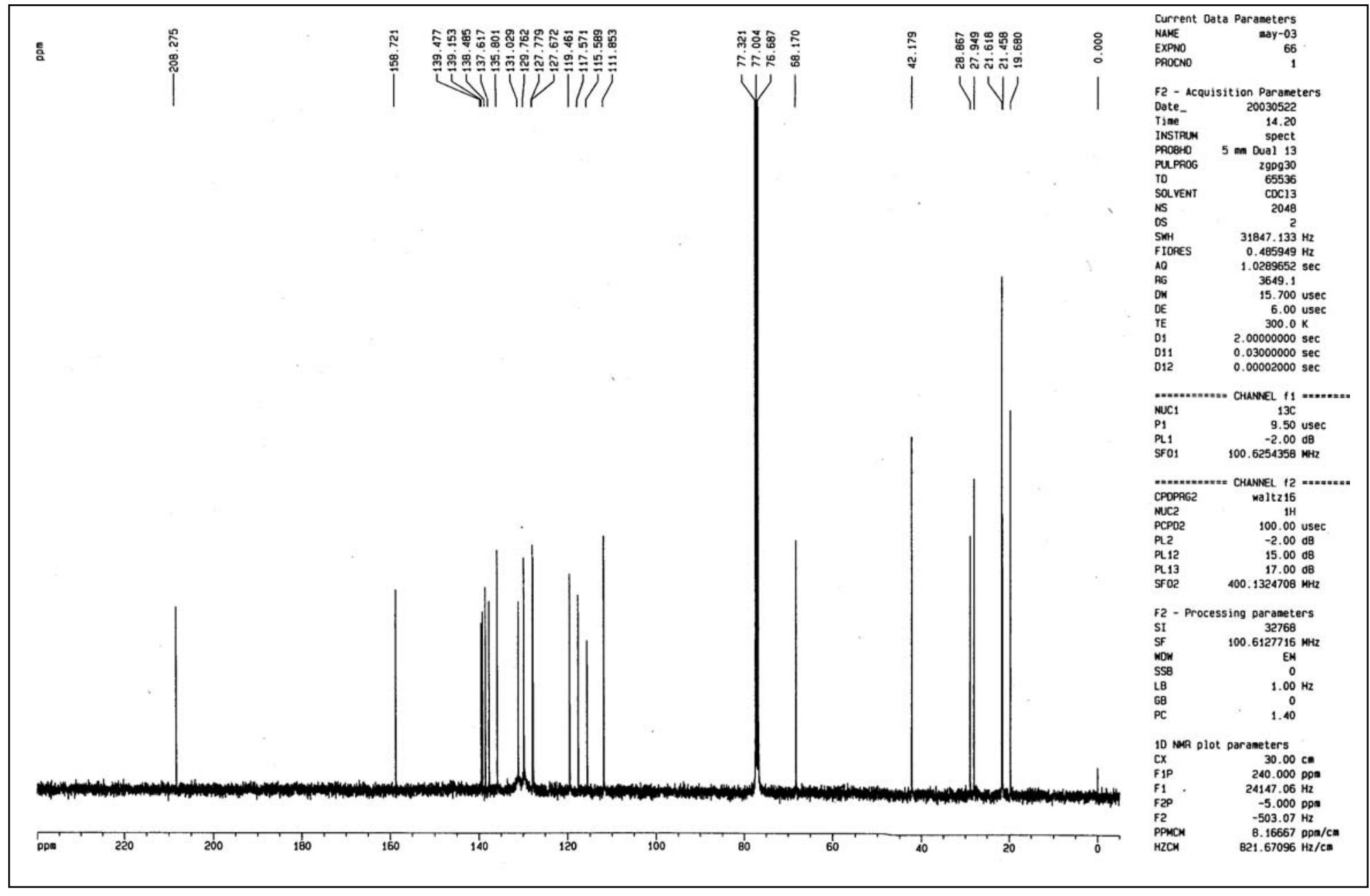


Fig.5. FAB-Mass spectrum of cis-Free base of 5,15-Bis-[2-(5-oxo-hexyloxy)-phenyl]10,20-bis-(2,4,6-trimethyl-phenyl) porphyrin (4).

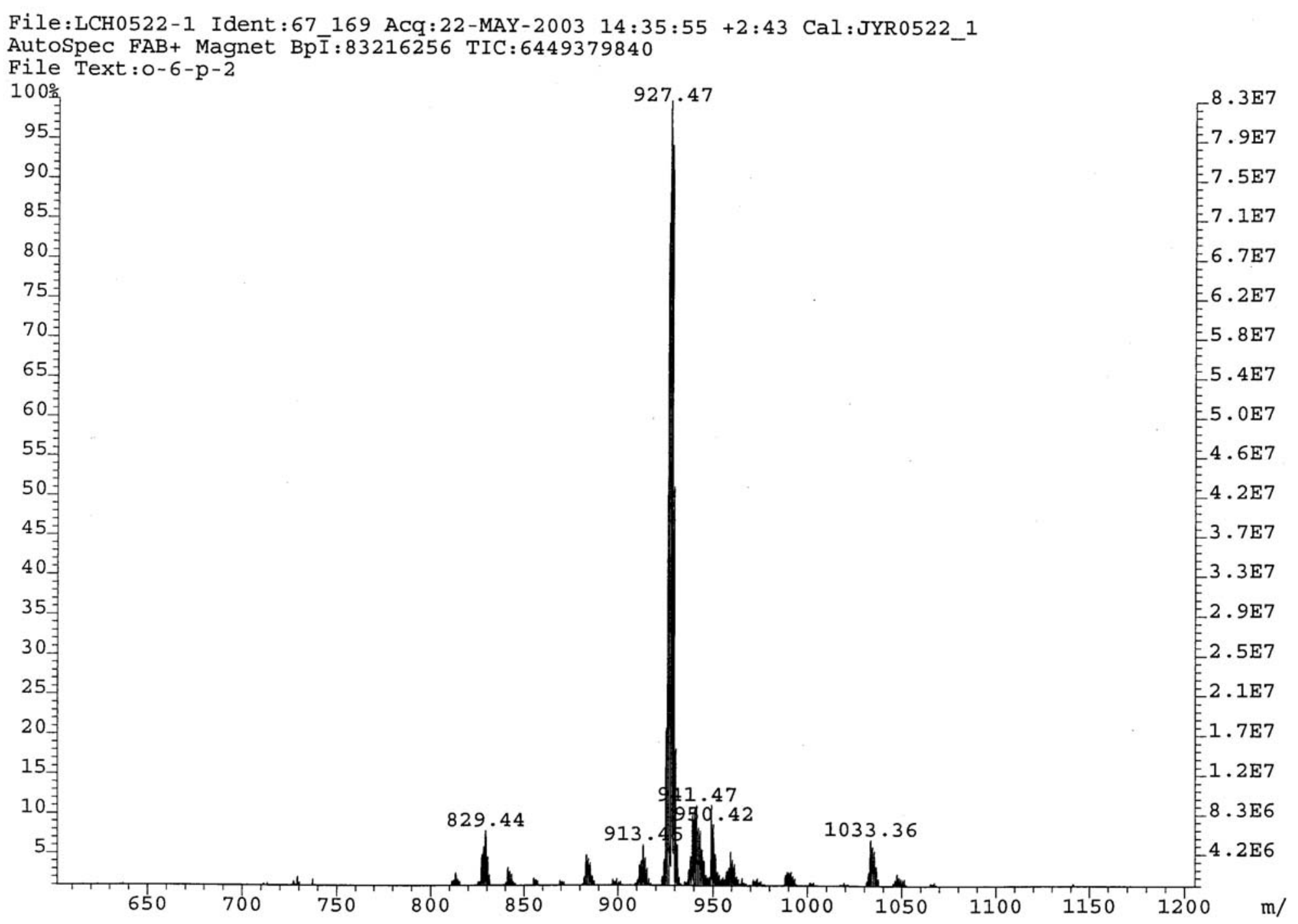


Fig.6. ${ }^{1} \mathrm{H}$ NMR spectrum of trans-Free base of 5,15-Bis-[2-(5-oxo-hexyloxy)-phenyl]10,20-bis-(2,4,6-trimethyl-phenyl) porphyrin (4).

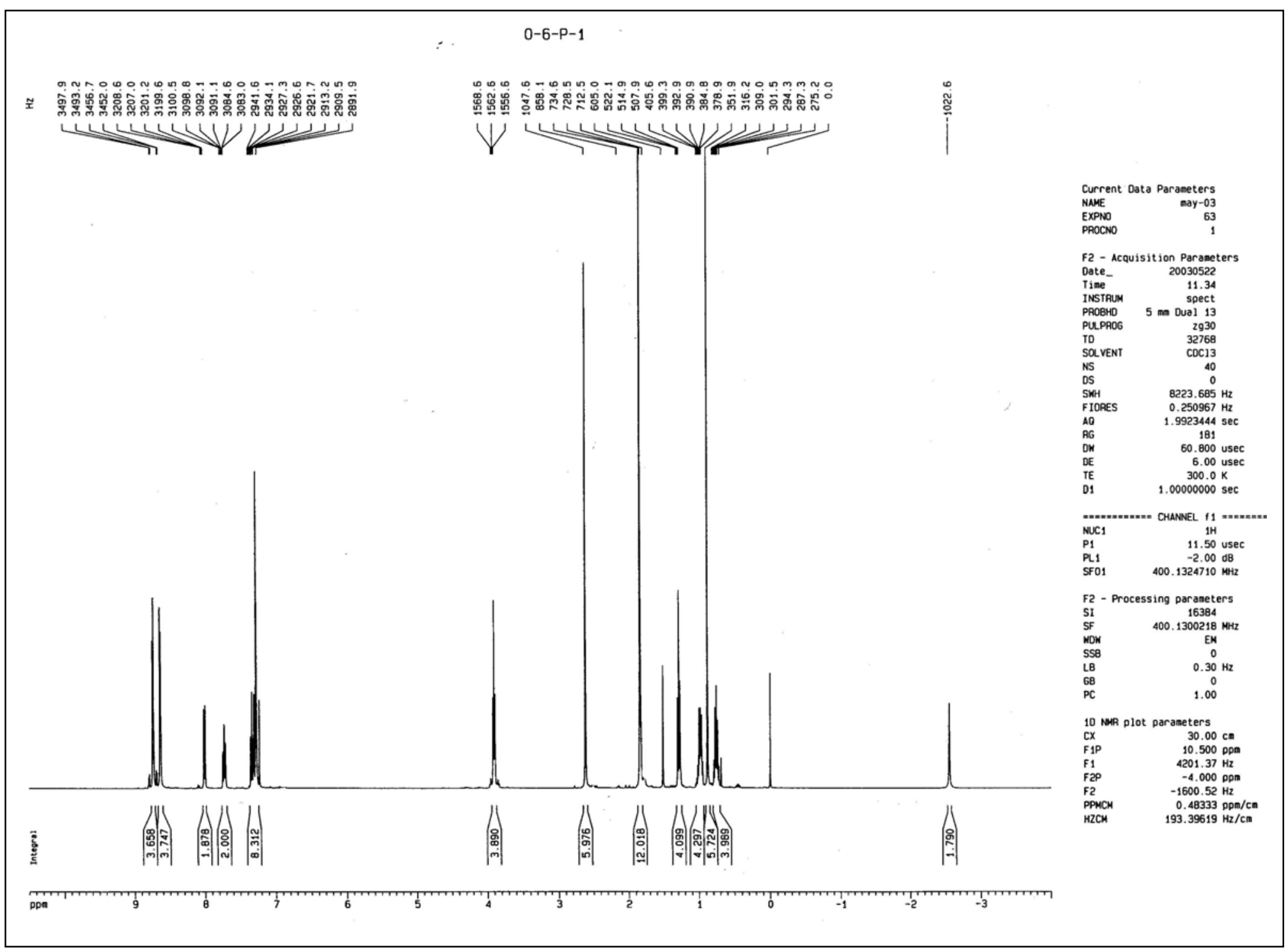


Fig.7. ${ }^{13} \mathrm{C}$ NMR spectrum of trans-Free base of 5,15-Bis-[2-(5-oxo-hexyloxy)phenyl]-10,20-bis-(2,4,6-trimethyl-phenyl) porphyrin (4).




Fig.8. FAB-Mass spectrum of trans-Free base of 5,15-Bis-[2-(5-oxo-hexyloxy)phenyl]-10,20-bis-(2,4,6-trimethyl-phenyl) porphyrin (4).

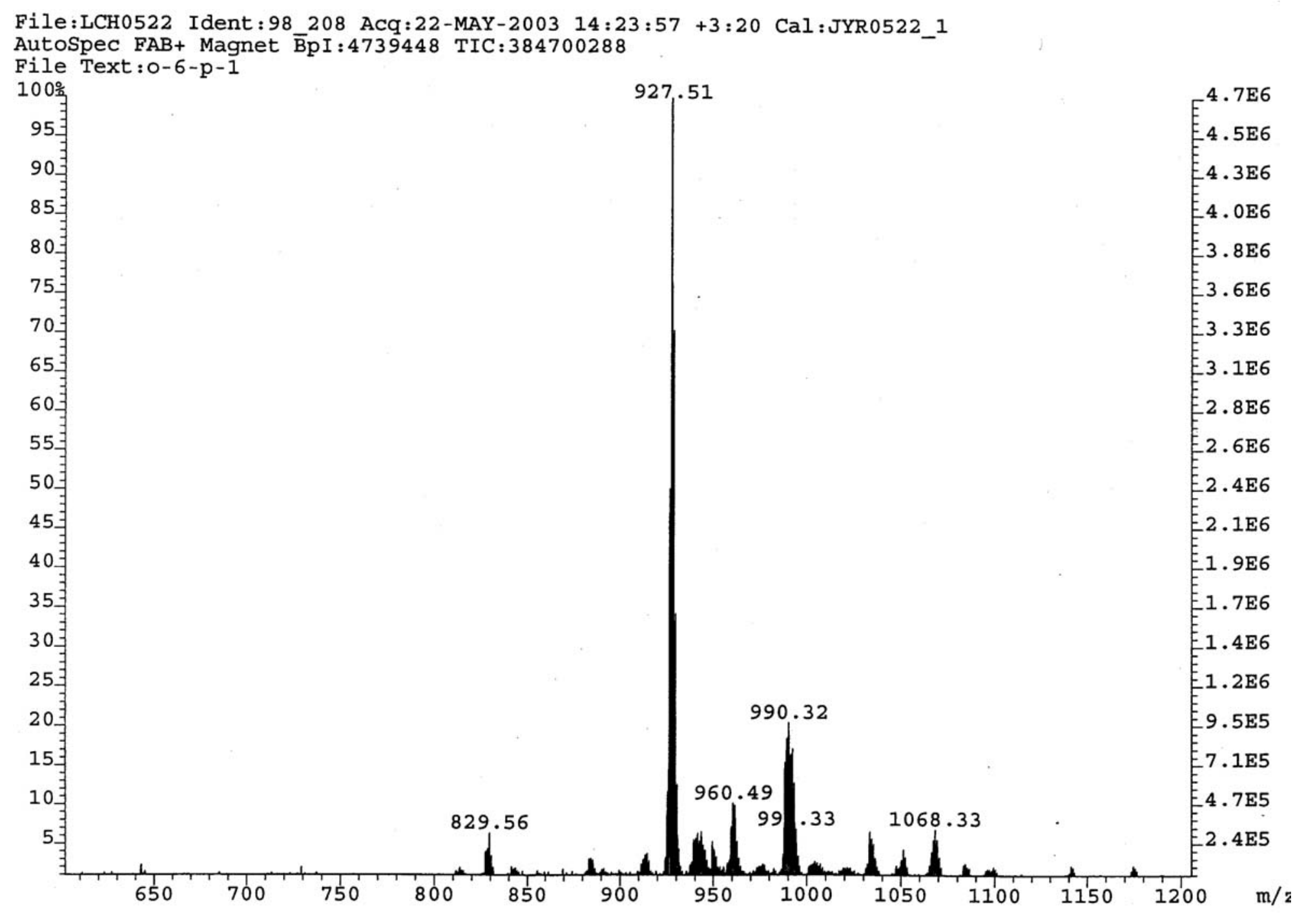


Fig.9. FAB-Mass spectrum of 5,15-bis-(2-(5-oxo-hexyloxy)-phenyl-10,20-bis-(2,4,6trimethyl-phenyl)porphyrinatonickel (II) (4).

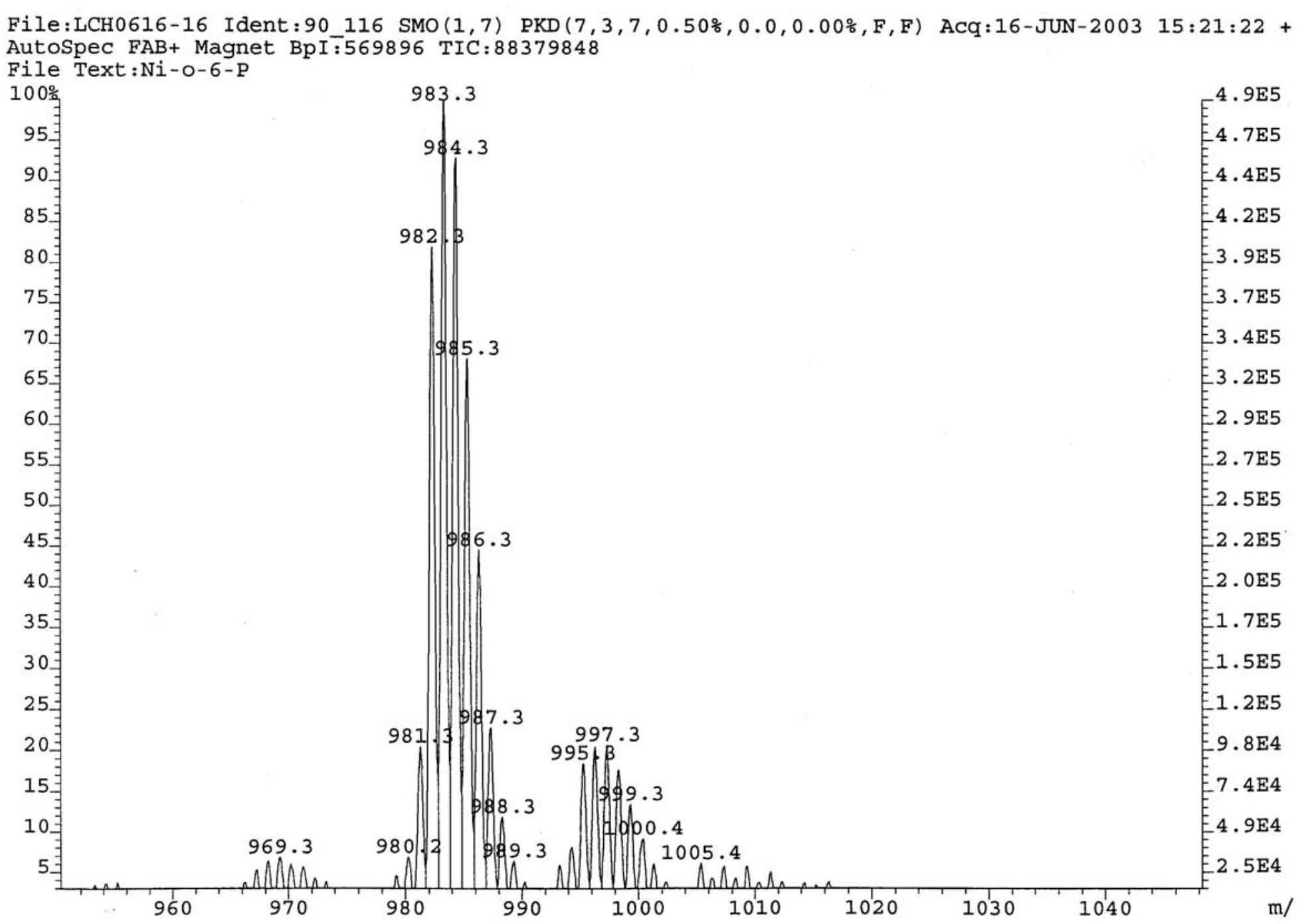


Fig.10. FAB-Mass spectrum of Ni(II)-porphyrin (5).

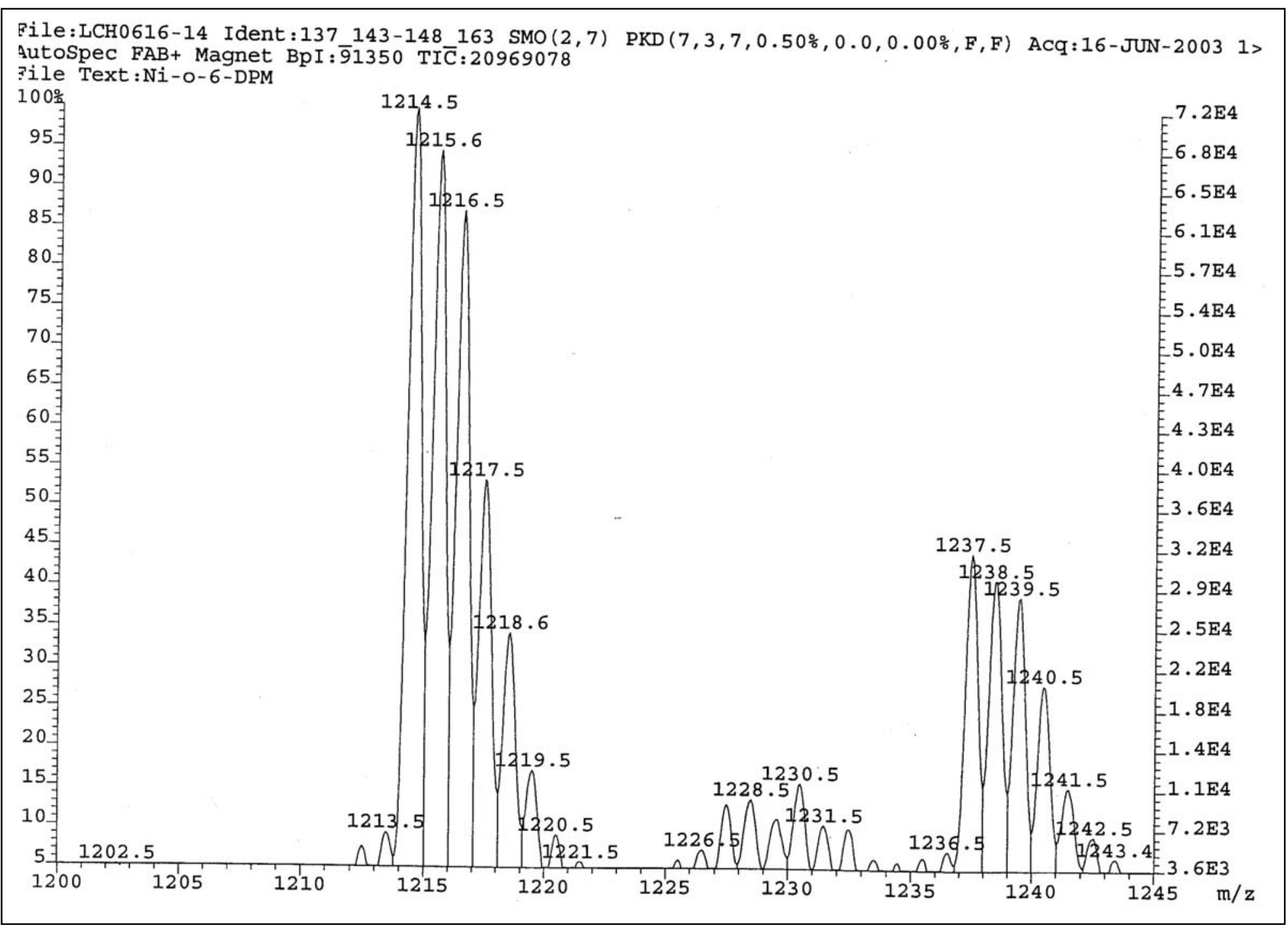


Fig.11. ${ }^{1}$ H NMR spectrum of Ni(II)-porphyrin-calix[4]pyrrole conjugate (cis) (6).

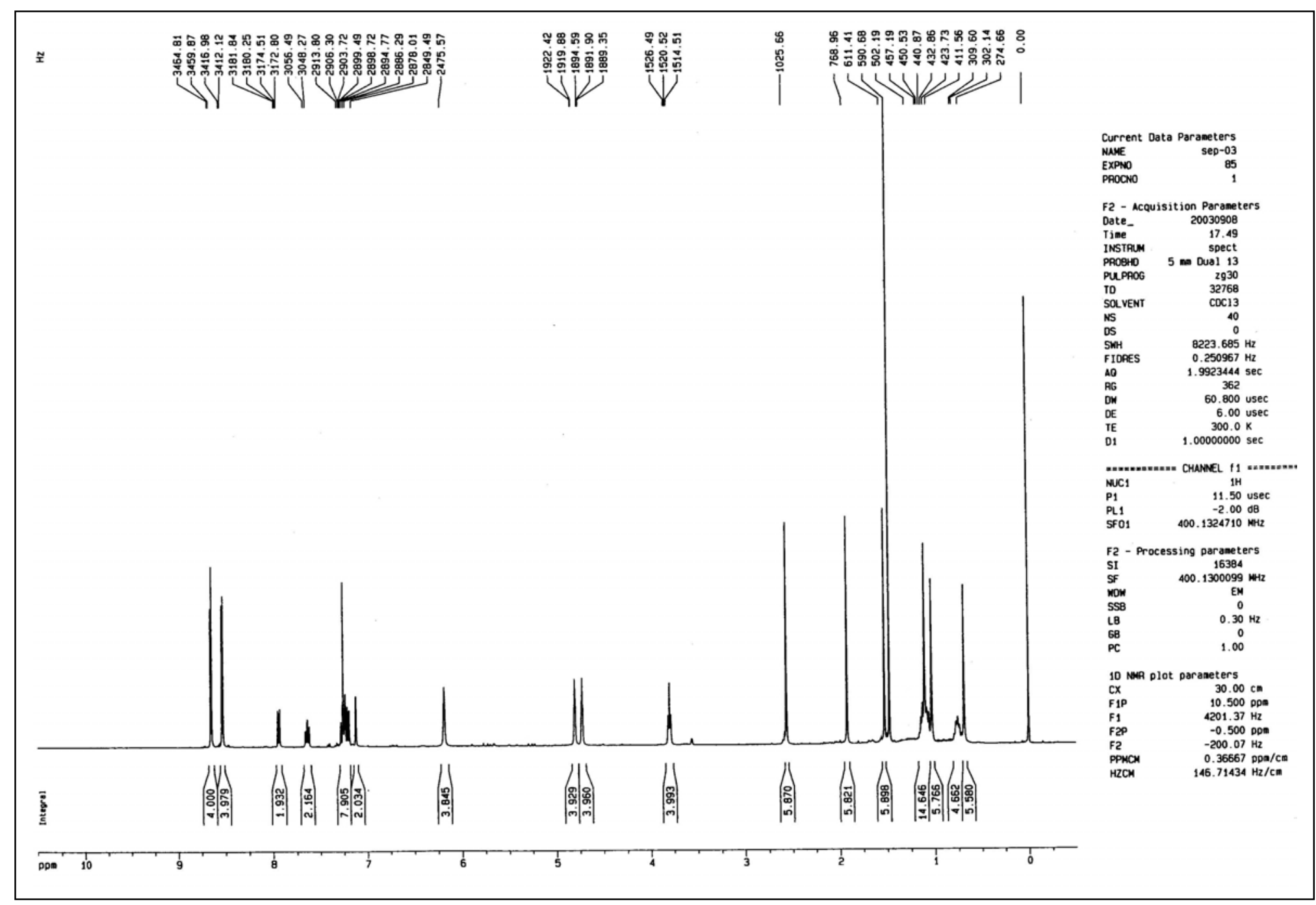


Fig.12. ${ }^{13} \mathrm{C}$ NMR spectrum of Ni(II)-porphyrin-calix[4]pyrrole conjugate (cis) (6).

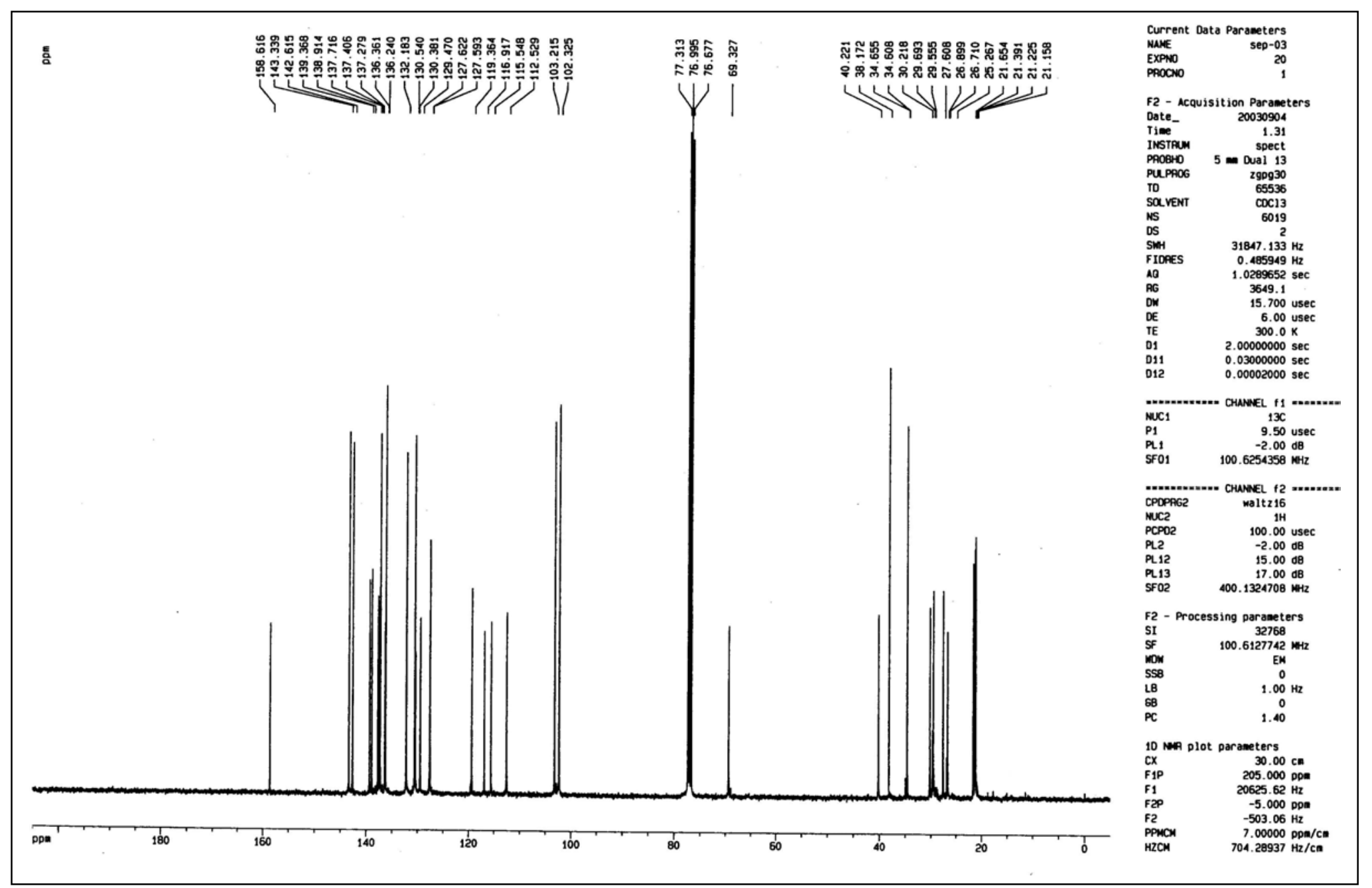


Fig.13. FAB-Mass spectrum of Ni(II)-porphyrin-calix[4]pyrrole conjugate (cis) (6).

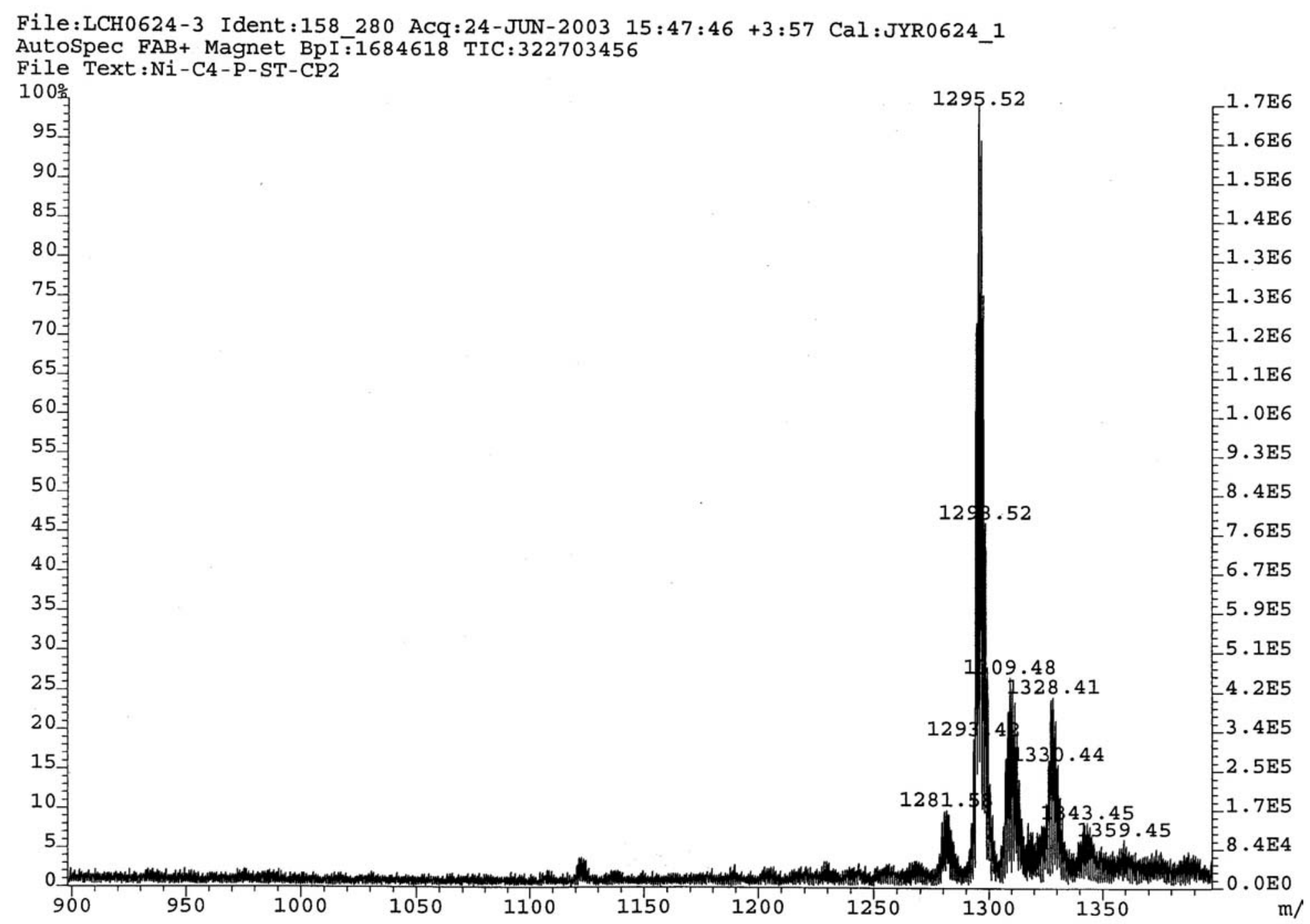


Fig.14. ${ }^{1} \mathrm{H}$ NMR spectrum of Ni(II)-porphyrin-calix[4]pyrrole conjugate (trans) (7).

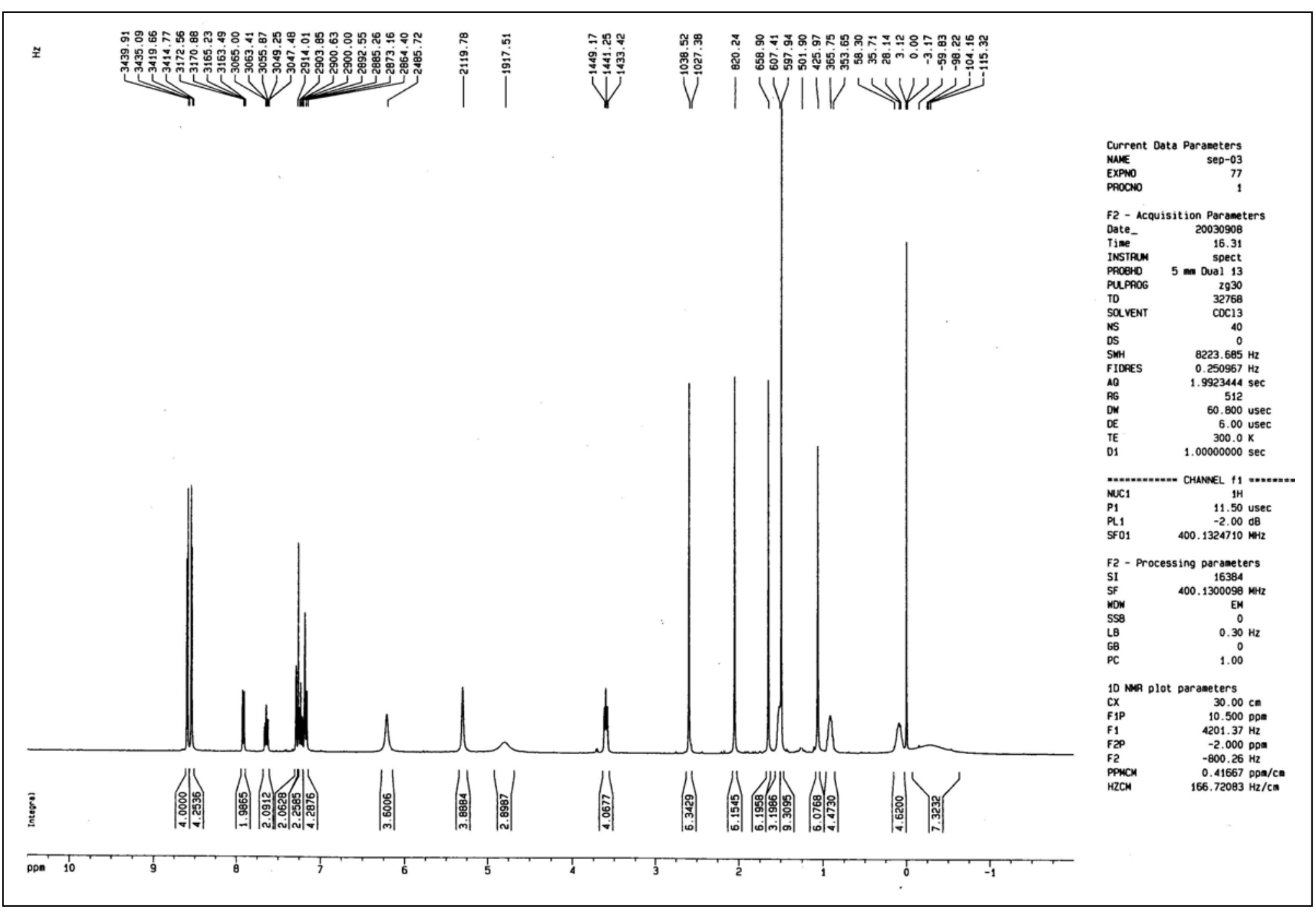


Fig.15. ${ }^{13} \mathrm{C}$ NMR spectrum of Ni(II)-porphyrin-calix[4]pyrrole conjugate (trans) (7).

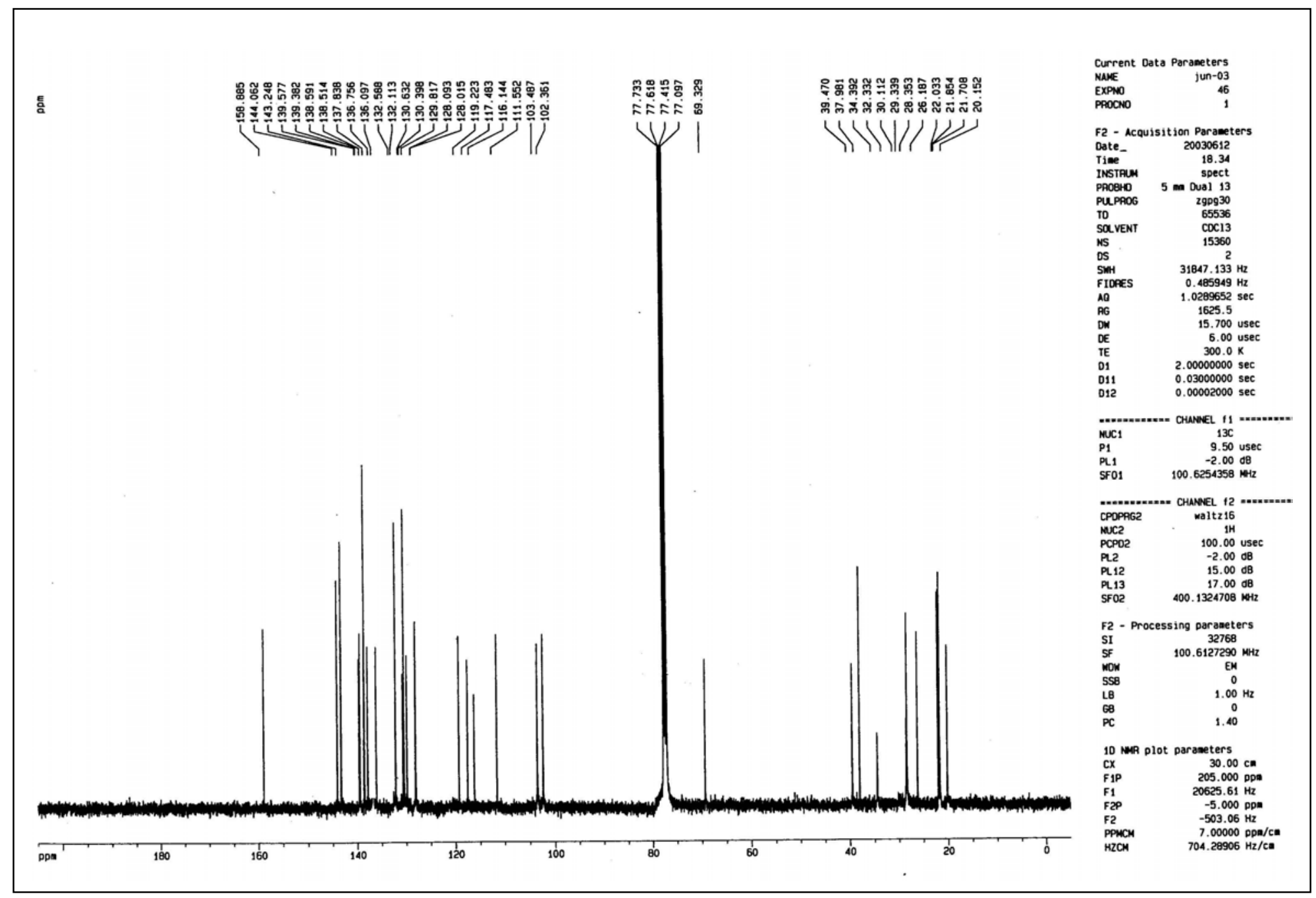


Fig.16. FAB-Mass spectrum of Ni(II)-porphyrin-calix[4]pyrrole conjugate (trans) (7).

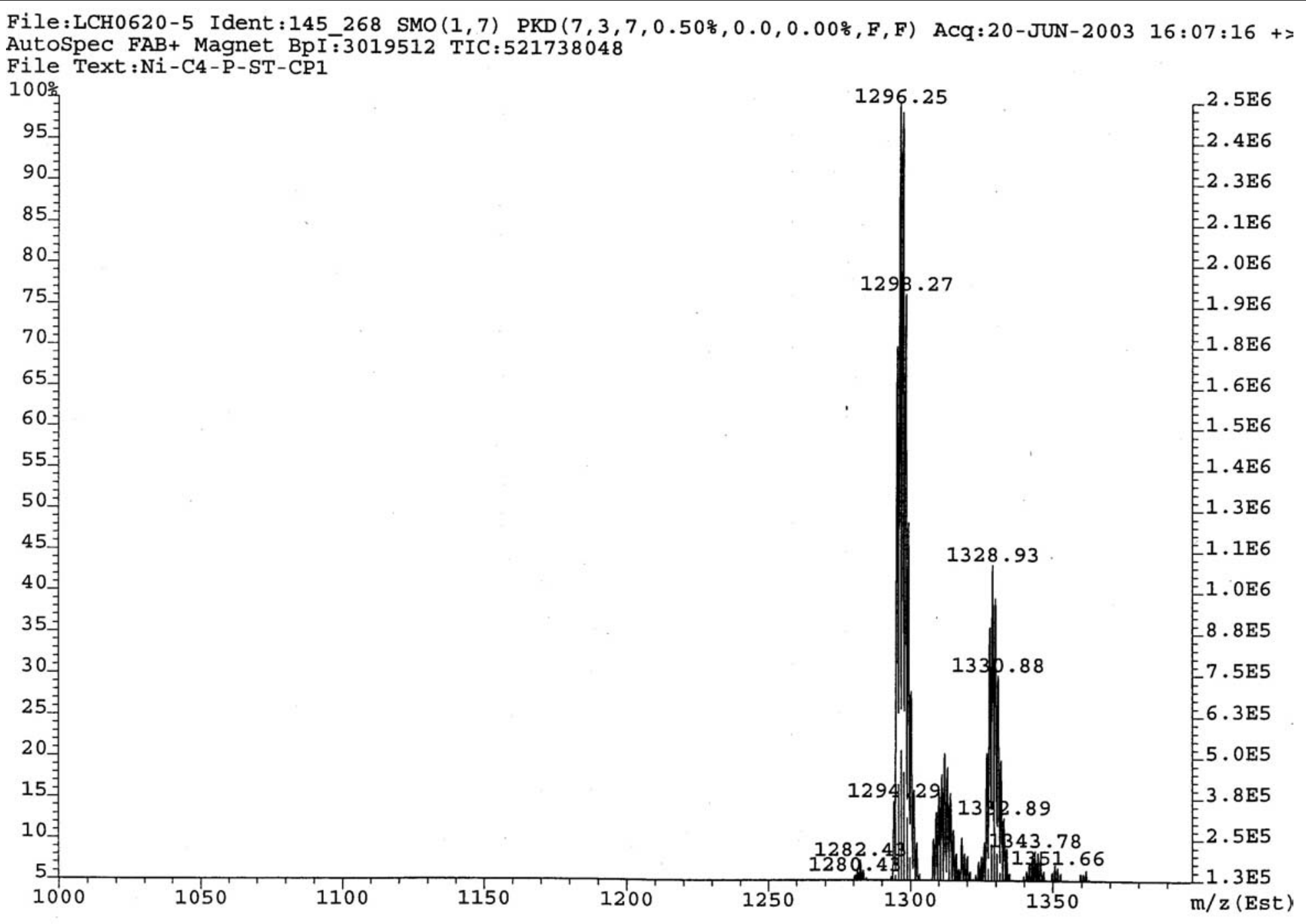


Fig.17. ${ }^{1} \mathrm{H}$ NMR spectrum of $\mathrm{Ni}(\mathrm{II})$-porphyrin-calix[4]pyrrole conjugate (cis) (6) in $\mathrm{CD}_{2} \mathrm{Cl}_{2}$ at room temperature (top) and $-50{ }^{\circ} \mathrm{C}$ (bottom).

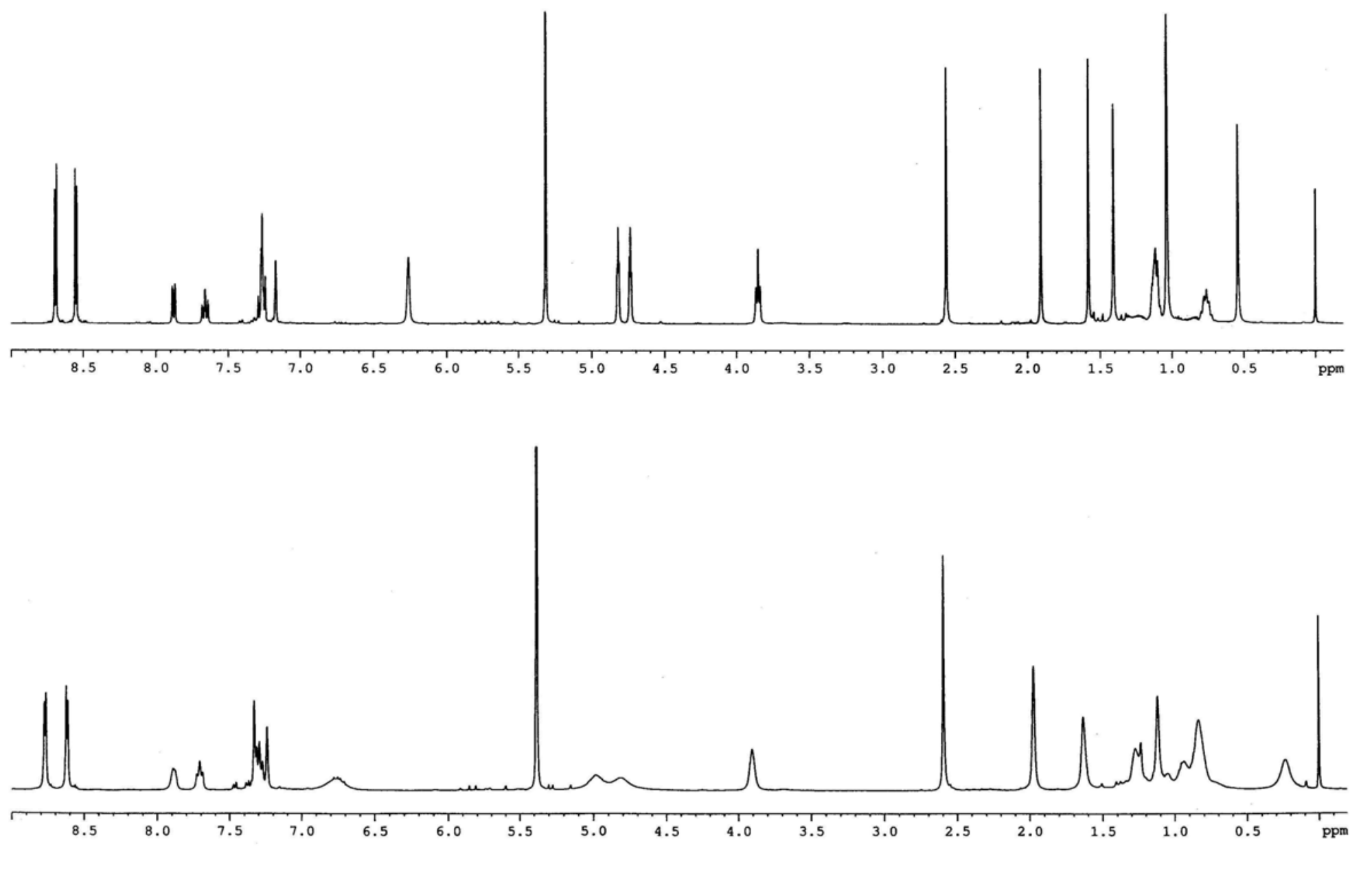


Fig.18. ${ }^{1} \mathrm{H}$ NMR spectrum of Ni(II)-porphyrin-calix[4]pyrrole conjugate (trans) (7) in $\mathrm{CD}_{2} \mathrm{Cl}_{2}$ at room temperature (top) and $-50{ }^{\circ} \mathrm{C}$ (bottom).
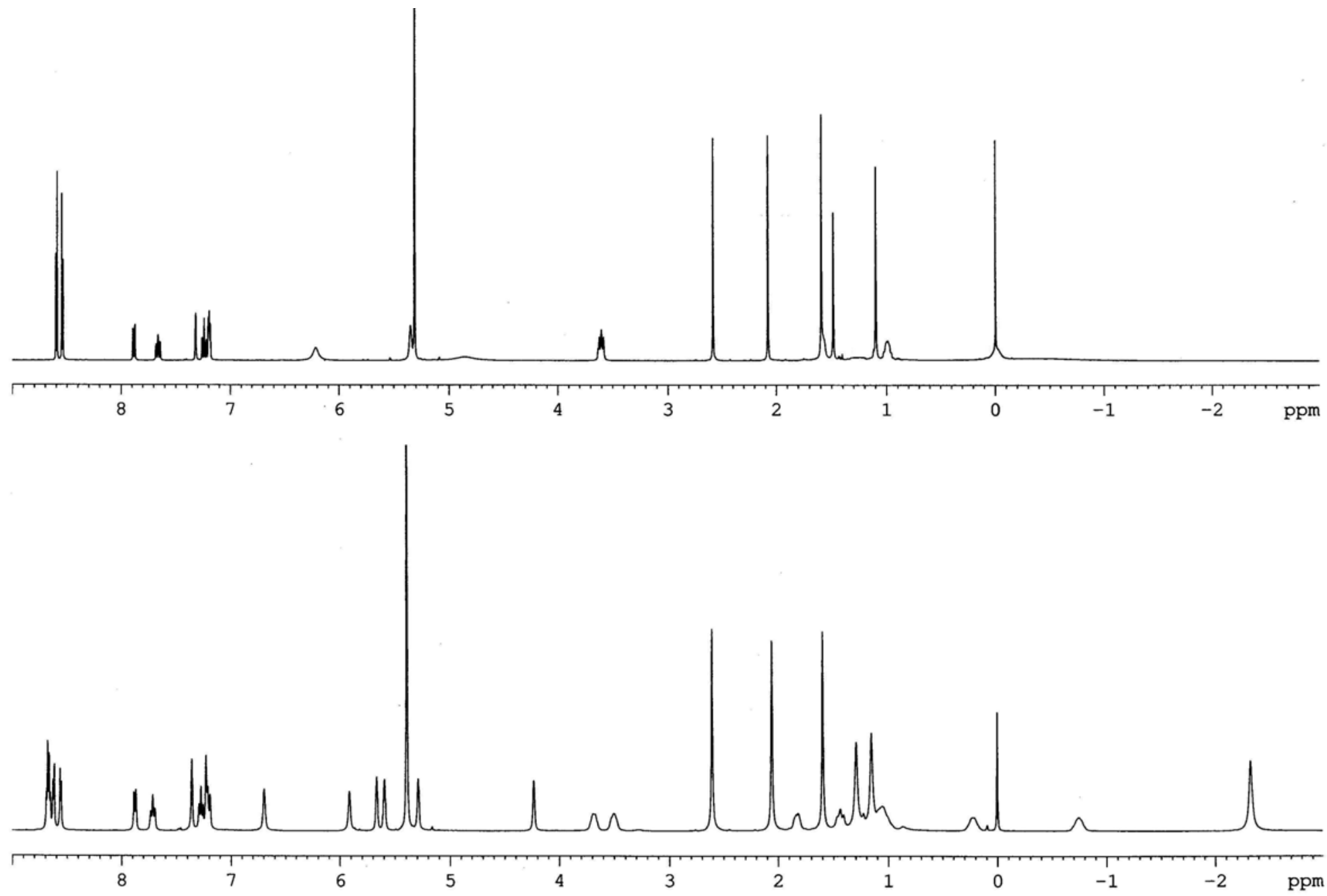
Fig.19. ${ }^{1} \mathrm{H}$ NMR spectrum of Ni(II)-porphyrin-calix[4]pyrrole conjugate (cis) (6) in $\mathrm{CDCl}_{3}: \mathrm{DMSO}_{-} \mathrm{d}_{6}(1: 3)$ at room temperature (top) and $120{ }^{\circ} \mathrm{C}$ (bottom).

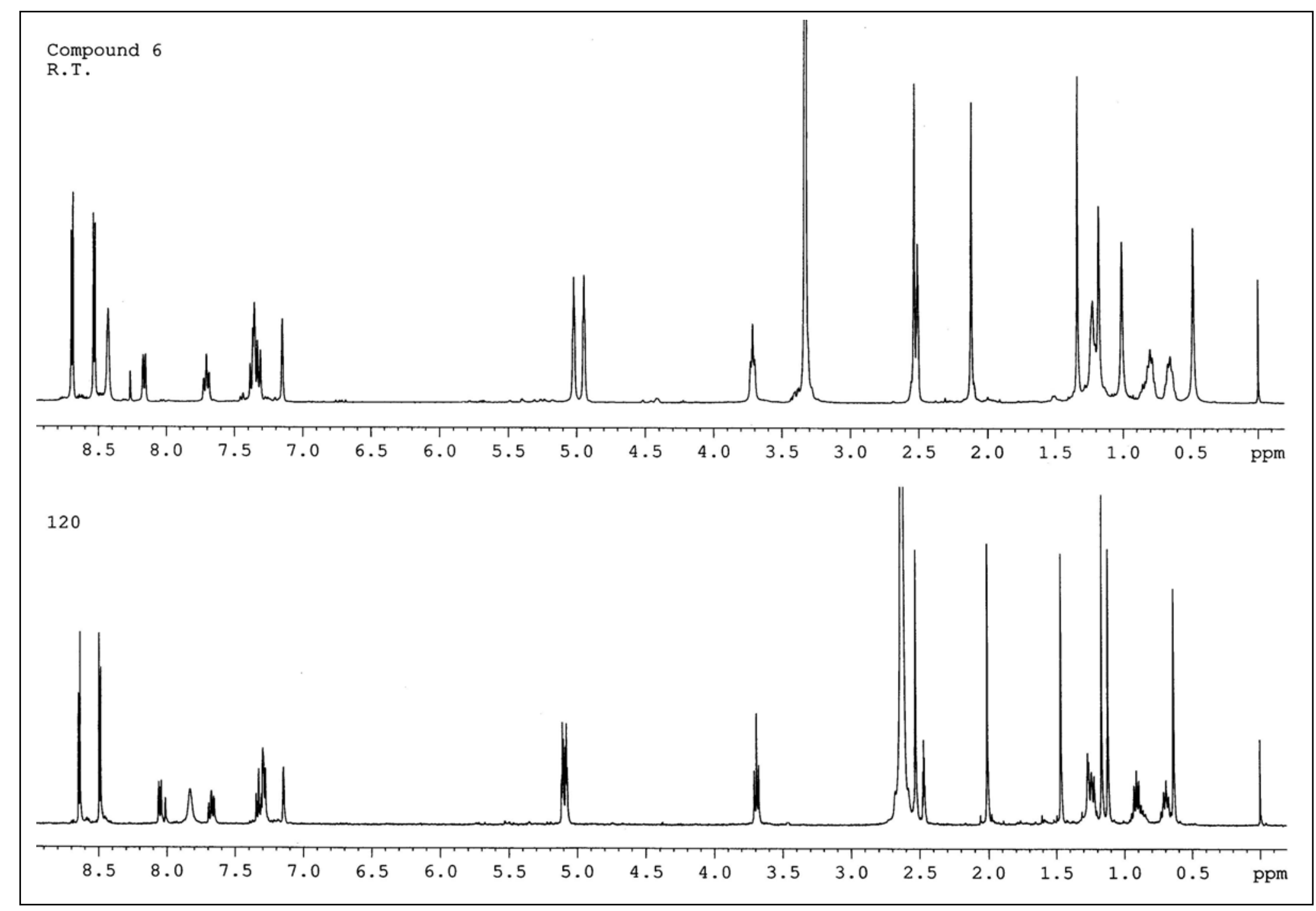


Fig.20. ${ }^{1} \mathrm{H}$ NMR spectrum of Ni(II)-porphyrin-calix[4]pyrrole conjugate (trans) (7) in $\mathrm{CDCl}_{3}$ :DMSO-d 6 (1:3) at room temperature (top) and $120^{\circ} \mathrm{C}$ (bottom).

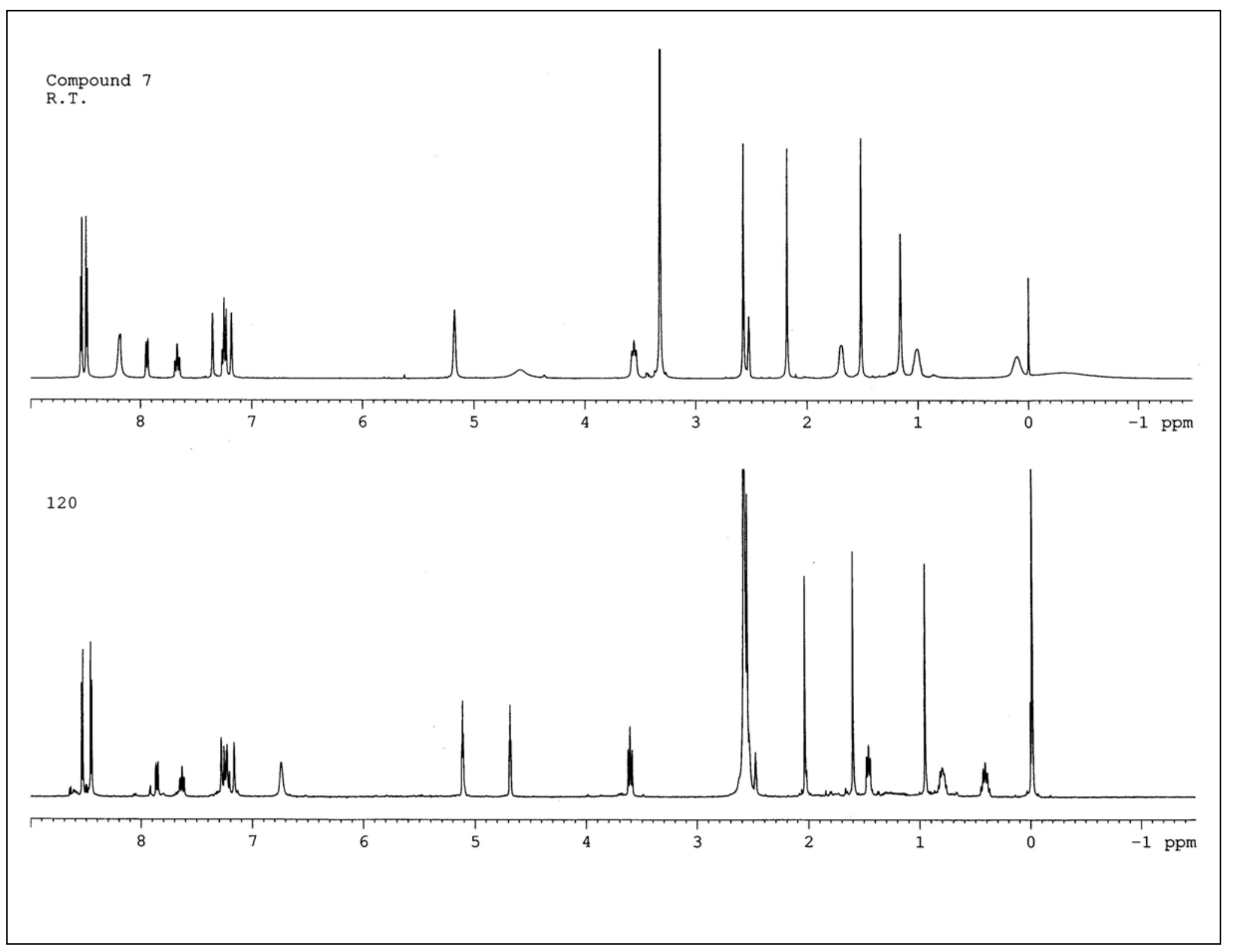


Fig. 21. ${ }^{1} \mathrm{H}$ NMR titration spectra of Ni(II)-porphyrin-calix[4]pyrrole conjugate (cis) (6) with tetrabutylammoniumfluoride in $\mathrm{CDCl}_{3}$.

Compound 6

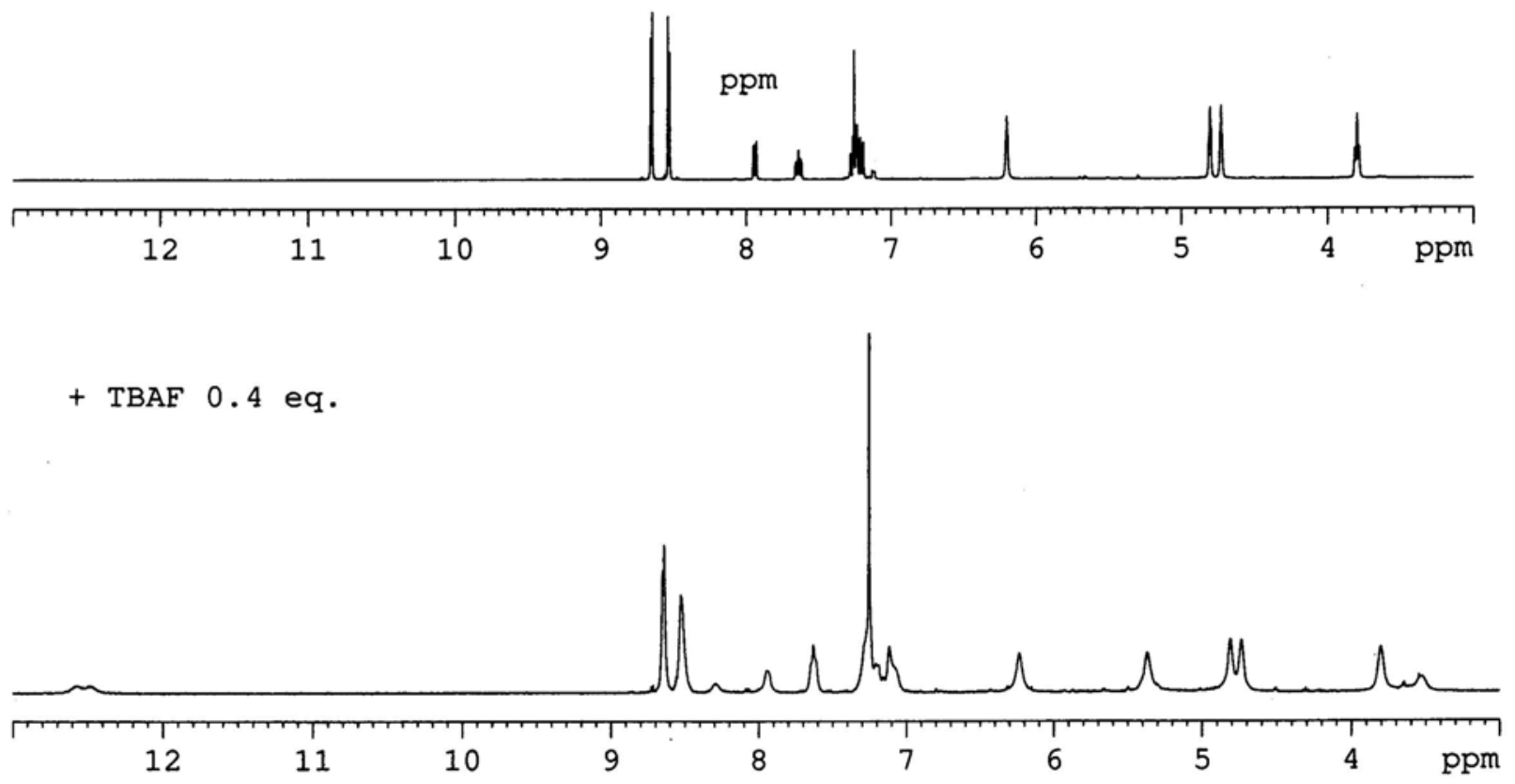

+ TBAF 0.8 eq.

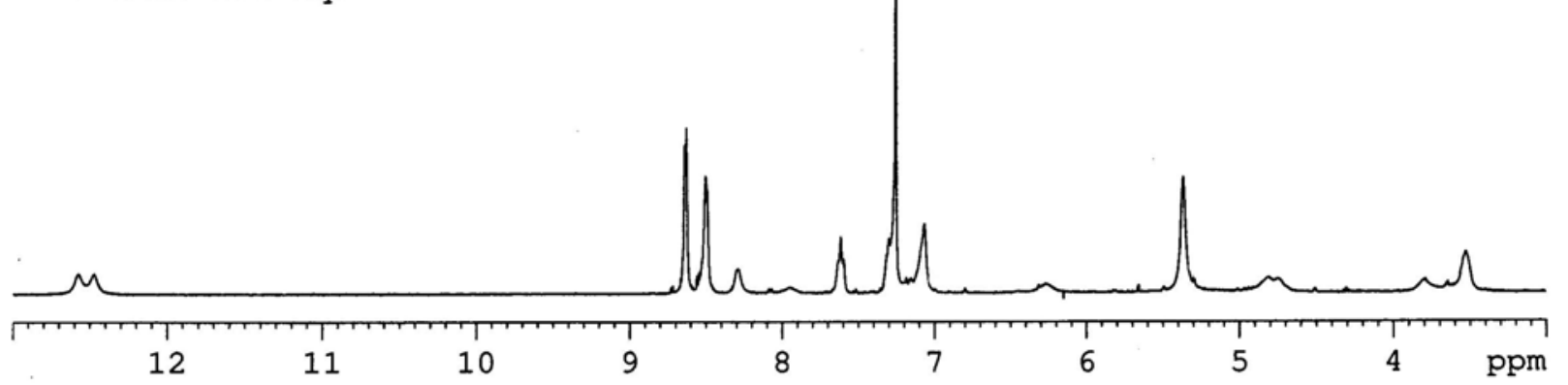

+ TBAF 1.1 eq.

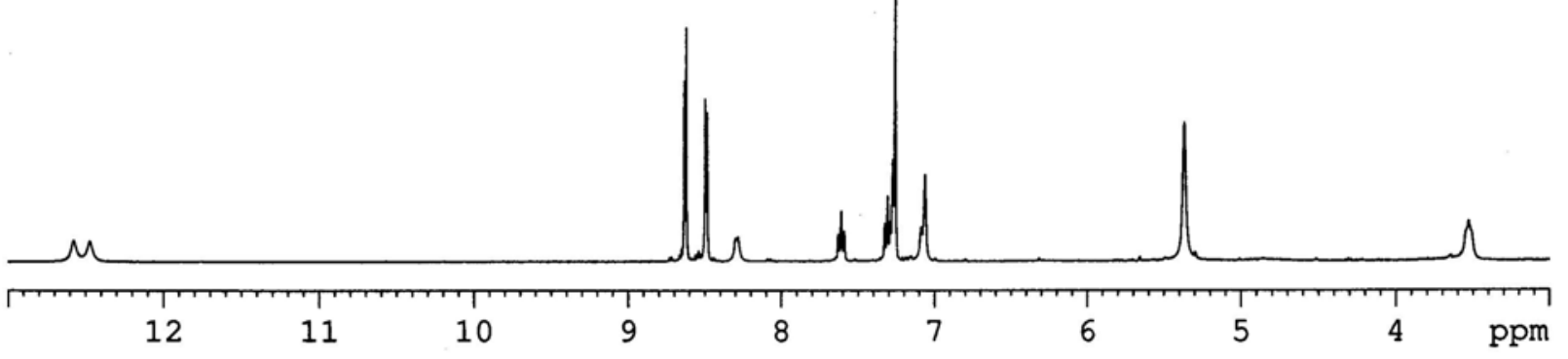


Fig. 22. ${ }^{1} \mathrm{H}$ NMR titration curve for Ni(II)-porphyrin-calix[4]pyrrole conjugate (cis) (6) with tetrabutylammoniumfluoride in $\mathrm{CDCl}_{3}$. The concentration of host is $5.32 \mathrm{mM}$.

Compound $6+$ TBAF




Figure 23. Job plot for the complexation of 6 with TBAF in $\mathrm{CDCl}_{3}$.

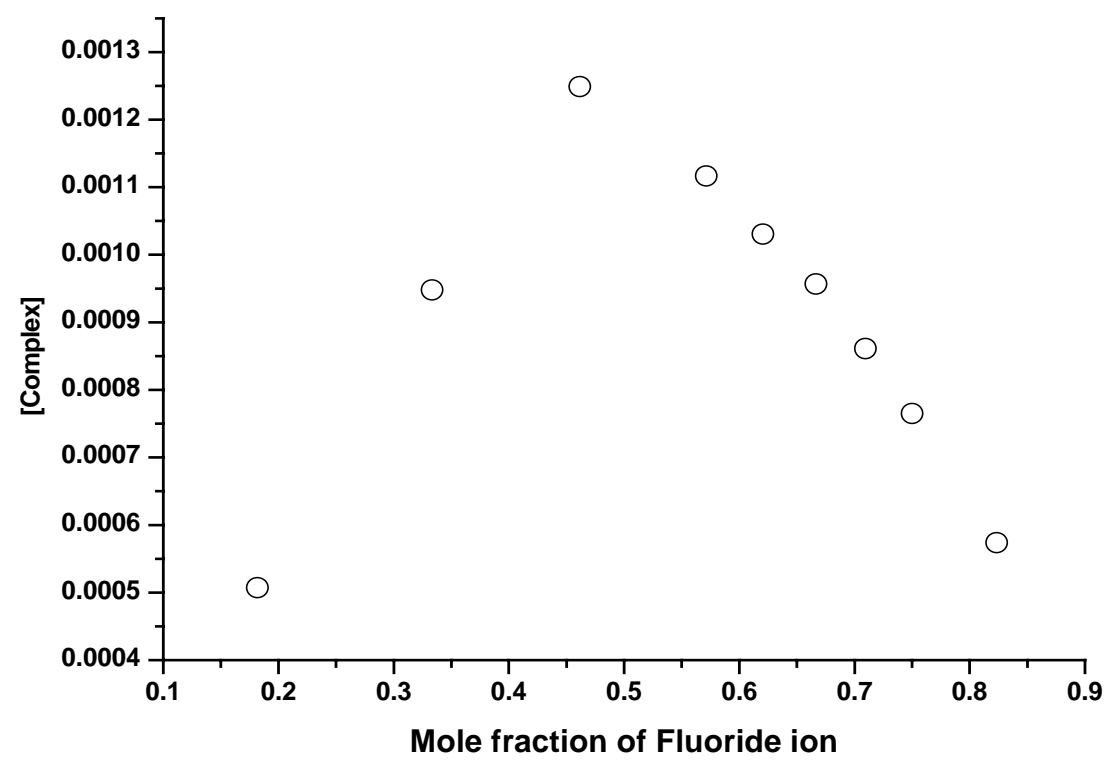

